\title{
NOTÍCIA
}

Sociologias, Porto Alegre, ano 6, no 11, Jan/Jun 2004, p. 344-350

\section{Os trinta anos da pós-graduação em Sociologia}

\author{
PPGs de Ciência Política e Sociologia vencem \\ os desafios*
}

O auditório do ILEA acolheu em junho cerca de 100 pessoas num evento comemorativo aos 30 anos dos cursos de pós-graduação de Ciência Política e Sociologia. Estiveram presentes na solenidade a reitora Wrana Maria Panizzi; o diretor do Instituto de Filosofia e Ciências Humanas (IFCH), José Vicente Tavares dos Santos; o ex-reitor, fundador do mestrado em Ciência Política e Sociologia e primeiro coordenador, Francisco Luiz dos Santos Ferraz; a professora de Ciência Política Mercedes Maria Loguercio Cánepa, representando o coordenador do curso, Carlos Schimidt Arturi; a coordenadora do PPG de Sociologia, Clarissa Eckert Baeta Neves; a professora de Sociologia Maria Susana Arrosa Soares; pró-reitores, professores, técnicos-administrativos e estudantes.

Para a professora Clarissa, o encontro foi um mergulho emocionante no passado. "No Brasil, as coisas se perdem muito rapidamente ou caem no esquecimento. Poder fazer parte dessa festa é uma enorme satisfação", afirma. Dividindo da mesma opinião da colega, a professora Mercedes diz sentir uma enorme admiração pela coragem dos idealizadores dos dois cursos. "Foi uma ousadia a criação de um mestrado em Ciência Política e Sociologia num dos nomentos de maior repressão do Regime Militar. Uma ousadia que deu certo", comemora.

Os cenários acadêmico e político do país, em 1973, em nada se assemelham aos dias de hoje. No Brasil dos anos 70, apenas cinco institui-

*Reportagem publicada no Jornal da Universidade - publicação da Coordenadoria de Comunicação Social da UFRGS Porto Alegre,RS, Brasil, anoV, no 64, p. 9, julho-agosto de 2003. 
ções ofereciam cursos de pós-graduação em Sociologia e duas em Ciência Política. E produzir pesquisa nas áreas de Ciências Sociais era uma grande aventura. "Quem fazia pesquisa naquela época era um Dom Quixote, já que não recebíamos auxílio das agências de fomento. Contávamos apenas com uma enorme vontade de aprender", lembra a professora Susana, aluna da segunda turma da graduação do curso de Ciências Sociais, criado em 1959.

Além da escassez de produção científica, professores e estudantes viviam a repressão dos anos de chumbo da ditadura, que censurava a atividade acadêmica. "Esse foi um dos dos paradoxos da ditadura militar. Se por um lado ela desenvolveu mecanismos de censura e patrulhamento, por outro permitiu um espaço positivo para que a pós-graduação se desenvolvesse nas áreas de Ciências Humanas", constata Susana.

Foi acreditando na capacidade de crescimento e concolidação das pós-graduações que o professor de Ciência Política Francisco Luiz dos Santos Ferraz - coordenador do curso integrado durante as duas primeiras gestões - levou adiante seu projeto, contando com a colaboração dos professores Hélgio Trindade, da Ciência Política, que vai sucedê-lo na coordenação e João Guilherme Corrêa de Souza, da Sociologia. Um dos principais desafios para o trio, que acabou tendo êxito, era incentivar a formação pós-graduada de professores dos cursos para ampliar o número de mestres, consolidando os programas.

Cinco anos mais tarde, é a vez da Antropologia passar a oferecer curso de mestrado junto com a Sociologia e a Política e fator parte do recém-criado Pacto do Vale, que estabelecia que a cada dois anos uma das três áreas indicaria o seu coordenador. Ele passaria a responder pelos cursos, com uma comissão constituída de dois docentes por área.

Recém-chegada do México, onde concluiu sua tese de mestrado, Susana foi eleita pelos colegas de trabalho a primeira coordenadora do novo sistema. "'Foi uma eleição consensuada. Meu nome tinha um bom trânsito tanto na Sociologia como na Ciência Política", recorda a professora. 
Administrar os três cursos, no entanto, não era uma tarefa fácil e, com o passar dos anos, essa responsabilidade crescia. Uma das razões da dificuldade era o aumento do número de professores que desembarcavam do exterior trazendo na bagagem o título de doutor. Na década de 80, a abertura de concursos públicos ampliou ainda mais o número do quadro de profissionais. E junto com o aumento do número de docentes, veio também o crescimento do número de estudantes.

A produção de pesquisa vai ganhando novos contornos, graças ao apoio da Finep para pesquisas nas três áreas, obtido ainda na gestão de Trindade. Com o passar do tempo, começavam a ficar cada vez mais evidentes os novos rumos que cada curso trilhava. Em 1981, a criação da Associação Nacional de Pós-Graduação em Ciências Sociais (Anpocs) vem selar os anseios dos profissionais em dar uma identidade própria para cada área.

Diante do novo cenário e do desejo comum de personalizar os cursos, a Ciência Política, a Sociologia e a Antropologia decidem constituir PPGs separadamente. "Antes da separação, não tínhamos um rosto muito definido perante a comunidade nacional. Essa decisão foi acertada e positiva para todos", avalia Clarissa.

\section{Ciência Política}

Na década de 60, o auxílio para pesquisa no Brasil era privilégio de poucos. Um convênio, porém, com duração de cinco anos, assinado em 1967 com a Fundação Ford, alavancou os trabalhos de pesquisa da disciplina de Ciência política, que tinha como professor titular na época o professor Leónidas Rangel Xausa - que viria a ser cassado em 1969 pelo regime militar.

O acordo, além de prever verbas para pesquisa, propiciou bolsas de formação pós-graduada no Brasil e no exterior. Além disso, possibilitou a 
aquisição de um acervo bibliográfico, originando a criação de uma biblioteca setorial de Ciência Política e Sociologia. "Este material constituiu base importante paro a criação do mestrado", lembra Mercedes.

Em 1968, através deste projeto, desenvolveu-se o survey sobre o comportamento político nas cidades de Porto Alegre e ljuí. Trata-se do segundo survey acadêmico do Brasil (amostra da população geral) na área de Ciência Política. "Para nossa sorte, a pesquisa foi realizada três meses antes do Al-5", diz Mercedes. Outro trabalho, pioneiro no Estado, promovido pelos entusiasmados estudantes vinculados ao projeto, foi o levantamento de todos os dados eleitorais e socioeconômicos do Estado desde 1945, promovendo um importante resgate da história gaúcha.

Em 1979, com o curso de mestrado já em andamento, é criado pelo professor Hélgio Trindade o Núcleo de Pesquisa e Documentação da Política Rio-Grandense (Nupergs), vinculado ao PPGCP, incorporando o acervo gerado pelas pesquisas desde 1968 e os arquivos de líderes da política gaúcha e nacional, como Assis Brasil, Flores da Cunha e Raul Pilla.

O Cone Sul já estava na rota dos pesquisadores. Por isso, foi posteriormente transformado em Nupergs-Consul, desenvolvendo estudos sobre a política brasileira e latino-americana. O núcleo oferece ainda, a professores e alunos, apoio aos trabalhos de dissertação, permitindo acesso ao acervo documental e a um banco de dados especializado.

Consolidado o mestrado, o doutorado começava a virar realidade. Sob a coordenação da Professora Céli Regina Jardim Pinto, iniciou suas atividades em 1996. A nova proposta enfatizou as áreas de Integração Latino-Americana e Estudos Comparados. Contou com o apoio formal da Associação de Universidades do Grupo Montevideo (que reúne universidades públicas da Argentina, Brasil, Uruguai e Paraguai). Para sua inauguração, foi realizado um seminário internacional: "Os desafios da democracia na América Latina". Na sessão de abertura do mesmo, o então Reitor Hélgio Trindade chamava atenção para a importância deste novo desafio 
acadêmico, idealizado de forma compartilhada desde o início da década de 90, e que contou, em sua configuração final, com a contribuição decisiva da coordenadora Céli.

Pelos corredores e salas de aulas do PPG vêm passando ao longo dos anos estudantes das mais diferentes partes do Brasil e de vários países da América Latina, como Argentina, Uruguai, Chile, Peru e Equador. Por meio de intercâmbios e da realização de eventos conjuntos, se mantém uma estreita articulação com universidades e instituições do exterior.

Atualmente, o PPG em ciência Política (mestrado e doutorado) conta com 15 professores, atuando em duas áreas de concentração: Política Brasileira e Política Comparada na América Latina, com suas respectivas linhas de pesquisa.

Atualmente, são duas áreas de concentração e sete linhas de pesquisa. Na primeira, Política Brasileira, são realizados os trabalhos intitulados Democracia e Representação; Estado, Partidos, Comportamento Político e Participação; Pensamento Social, Elites e Instituições; Análise Política na Contemporaneidade. Na segunda área de concentração, Política Comparada na América Latina, estão em andamento as pesquisas Estado, Instituições e Políticas Educacionais; Estado, Partidos, Comportamento Político e Cultura Política na América Latina; Política Internacional e Integração Regional.

\section{Sociologia}

A década de 70 se inicia promissora para a Sociologia. Além da criação do PPG, um acordo com a Obra Ecumênica de Estudos, programa financiado pela Igreja Evangélica da Alemanha, sob a batuta do professor alemão Achim Schrader, viabilizou aos estudantes 40 bolsas de estudo, com a possibilidade de escolha do país destinatário. "Era uma oportunidade de sairmos temporariamente do Brasil, naquele período nebuloso de 
ditadura, para a produção de trabalhos que contribuiriam para o futuro de nossa Universidade", avalia Susana.

Em 1982, porém, uma crise abala o curso. A V Câmara de Pós-Graduação da Universidade dá um ultimato à direção: ou se ampliava o número de doutores, ou o curso acabaria. "Nós nos sentimos desafiados e decidimos mostrar que seria possível duplicar o número de doutores em três anos. E cumprimos rigorosamente o acordo", lembra Susana.

A separação dos cursos, em 1985, traz novos ares ao PPG de Sociologia, gerando autonomia e consolidação. O curso expande-se ainda mais através da fusão com o mestrado da Sociologia Rural, que era vinculada ao Instituto de Pesquisas Econômicas da Faculdade de Economia. Surge, então, um novo PPG, resultante da junção das duas áreas. Com um suporte grande e forte, chegava a hora de se começar a pensar na criação do doutorado, implementado em 94.

O trabalho desenvolvido pelos 23 doutores da Sociologia tem rendido bons frutos e ultrapassado barreiras geográficas. Tanto que a procura pelo PPG por estudantes latino-americanos vem crescendo nos últimos anos. Os brasileiros dividem as salas de aula com colegas mexicanos, peruanos, chilenos e uruguaios, vindos de seus países de origem com o auxílio de bolsas de estudo. Para Clarissa, tamanha procura causa admiração, mas ela admite ser um coroamento do esforço empenhado pela equipe de docentes ao longo dos anos. "Sempre desenvolvemos um trabalho sério", orgulha-se.

Desde os tempos remotos, quando a pesquisa ainda era escassa, lá se vão mais de três décadas. Hoje, o PPG de Sociologia tem tradição neste assunto e soma, atualmente, sete linhas de pesquisa, todas ligadas às disciplinas Sociedade e Agricultura; Trabalhos nas Sociedades Contemporâneas; Sociedade e Conhecimento; Violência e Cidadania; Sociologia, História e Paradigmas, Políticas e Projetos Sociais; e Cidades, Estado e Direito. Além das linhas, há os grupos de estudo, como o grupo do Mercosul, Violência e Cidadania, Núcleo de Estudos sobre o Trabalho, entre outros. 
Sociologias, Porto Alegre, ano 5, no 10, jul/dez 2003, p. 412-442

Uma das áreas de pesquisa que vêm se fortalecendo é a de Agricultura. Produz trabalhos relacionados à exclusão social, a movimentos sociais no campo, questões relacionadas ao pequeno agricultor, questões de gênero, movimento dos sem-terra.

As mudanças delineadas pela tecnologia no mundo do trabalho também são alvo de estudo. As pesquisas permeiam os setores secundários, em especial os terciários, onde há grande inovação tecnológica - como o segmento de telefonia, por exemplo.

Além das linhas tradicionais, novos temas vêm despertando o interesse dos pesquisadores. Um deles, intitulado Violência e Cidadania, coordenado pelo professor José Vicente Tavares dos Santos, acompanha o desenho da violência e da criminalização nas principais capitais da América-Latina. "Nossa produção científica vem sendo difundida em eventos nacionais e internacionais e publicada em periódicos qualificados e reconhecidos pela comunidade científica", diz Clarissa. 